\title{
Dual ectopic thyroid associated with thyroid hemiagenesis
}

\author{
Shigenori Nakamura, Teruyuki Masuda and Masatoshi Ishimori
}

Thyroid and Diabetic Division, Department of Internal Medicine, Japanese Red Cross Gifu Hospital, Gifu, Japan

Correspondence should be addressed to S Nakamura

Email

s-nakamura@gifu-med.jrc. or.jp

\section{Summary}

We report a case of a 15-year-old girl with a midline neck mass that was first noted 2 or 3 years previously. She had been treated with levothyroxine (L-T4) for congenital hypothyroidism until 11 years of age. Ultrasonography revealed an atrophic right thyroid $(1.0 \times 1.6 \times 2.6 \mathrm{~cm}$ in size $)$ and a mass $(2.3 \times 1.0 \times 3.5 \mathrm{~cm}$ in size $)$ in the upper part of the neck. No left lobe of the thyroid was detected. On further evaluation, Tc- $99 \mathrm{~m}$ pertechnetate thyroid scintigraphy and CT showed ectopic thyroid tissue in the lingual region and infrahyoid region. Thus, she was diagnosed as having dual ectopic thyroid and thyroid hemiagenesis. The atrophic right thyroid was thought be non-functional. Treatment with L-T4 was started to reduce the size of the dual ectopic thyroid tissue. This may be the first reported case of dual ectopic thyroid associated with hemiagenesis detected only by ultrasonography.

\section{Learning points:}

- Ultrasonography can confirm the presence or absence of orthotopic thyroid tissue in patients with ectopic thyroid.

- The cause of congenital hypothyroidism should be examined.

- Clinical manifestation of ectopic thyroid may appear when the treatment with L-T4 is discontinued.

- Annual follow-up is needed in all children when their thyroid hormone replacement is stopped.

\section{Background}

Ectopic thyroid tissue is a rare congenital anomaly characterized by the presence of thyroid tissue in regions other than its normal position, usually from the base of the tongue to the final pre-tracheal position. The prevalence of ectopic thyroid is about 1 per $100,000-300,000$ individuals (1). It is very uncommon for ectopic thyroid tissue to be present simultaneously in two regions $(2,3)$. Thyroid hemiagenesis is also a rare congenital anomaly in which one lobe of the thyroid gland is not developed. It is generally diagnosed incidentally in association with abnormalities of the remaining opposite thyroid lobe, such as hyperthyroidism, hypothyroidism and adenoma. Korpal-Szczyrska et al. (4) detected thyroid hemiagenesis in two out of 4,004 unselected school children (aged 7-15 years) by ultrasonography (i.e. about 1 per 2,000).
Here, we report the case of a patient with dual ectopic thyroid associated with thyroid hemiagenesis.

\section{Case presentation}

A 15-year-old girl was referred to our hospital for further evaluation of her 2- or 3-year history of anterior neck swelling. She presented with occasional feelings of discomfort and pressure in the neck and a choking sensation. Her medical history demonstrated hypothyroidism that was detected by neonatal screening (thyroid-stimulating hormone (TSH) level: $78.5 \mu \mathrm{U} / \mathrm{mL}$; free T4 level: $1.05 \mathrm{ng} / \mathrm{dL}$ ) and treated with levothyroxine (L-T4) up to 11 years of age (the first dose of L-T4 was $30 \mu \mathrm{g} /$ day and the final dose of L-T4 was $5 \mu \mathrm{g} /$ day). 
A morphological examination was not performed when her hypothyroidism was first detected. Treatment with L-T4 was discontinued because a euthyroid status was achieved with a small dose of L-T4. She had no history of neck surgery or irradiation. Her family history revealed no other family members with thyroid disease.

\section{Investigation}

Her height was $165.5 \mathrm{~cm}$ and her body weight was $59.9 \mathrm{~kg}$. Her physical examination revealed a soft nontender mass $(2 \times 2 \mathrm{~cm}$ in size $)$ in the upper part of the anterior neck, but the thyroid gland was not palpable in the normal position. The serum levels of free T4, TSH and thyroglobulin $(\mathrm{Tg})$ were $1.01 \mathrm{ng} / \mathrm{dL}$ (normal range: $0.70-1.80 \mathrm{ng} / \mathrm{dL}$ ), $2.622 \mu \mathrm{U} / \mathrm{mL}$ (normal range: $0.40-$ $4.30 \mu \mathrm{U} / \mathrm{mL}$ ) and $24.2 \mathrm{ng} / \mathrm{mL}$ (normal range: $\leq 33.7 \mathrm{ng} /$ $\mathrm{mL}$ ), respectively. Anti-Tg, anti-peroxidase and anti-TSH receptor antibodies (TRAb) were negative. The serum $\mathrm{Tg}$ and TRAb were measured because they were useful to distinguish between the various causes of neonatal hypothyroidism. Ultrasonography demonstrated a heterogeneous mass $(2.3 \times 1.0 \times 3.5 \mathrm{~cm}$ in size $)$ in the upper part of the neck (Fig. 1) and an atrophic right thyroid lobe $(1.0 \times 1.6 \times 2.6 \mathrm{~cm}$ in size), but no left thyroid lobe was detected (Fig. 2). She was diagnosed as having thyroid hemiagenesis on the basis of these findings. Tc-99m pertechnetate thyroid scintigraphy (Fig. 3) showed uptake in the upper part of the neck and the center of the oral cavity, without uptake in the normal position of the thyroid or other positions. Neck CT (Fig. 4) revealed two hyperdense masses at the base of the tongue and in the pre-tracheal region below the hyoid bone, but not in the normal position. She was additionally diagnosed as having dual ectopic thyroid on the basis of these CT findings. Fine-needle aspiration biopsy of the pre-tracheal mass did not show malignant cells.

\section{Treatment}

Treatment with L-T4 was started to reduce the size of ectopic thyroid tissue.

\section{Outcome and follow-up}

She still complained of the symptoms when she had been treated with $50 \mu \mathrm{g} / \mathrm{day}$ of L-T4 for 10 weeks. At that time, serum levels of TSH and Tg were $0.725 \mu \mathrm{U} / \mathrm{mL}$ and $36.8 \mathrm{ng} /$ $\mathrm{mL}$, respectively. Thus, the dose of L-T4 was increased in order to suppress the activity of the ectopic thyroid tissue.

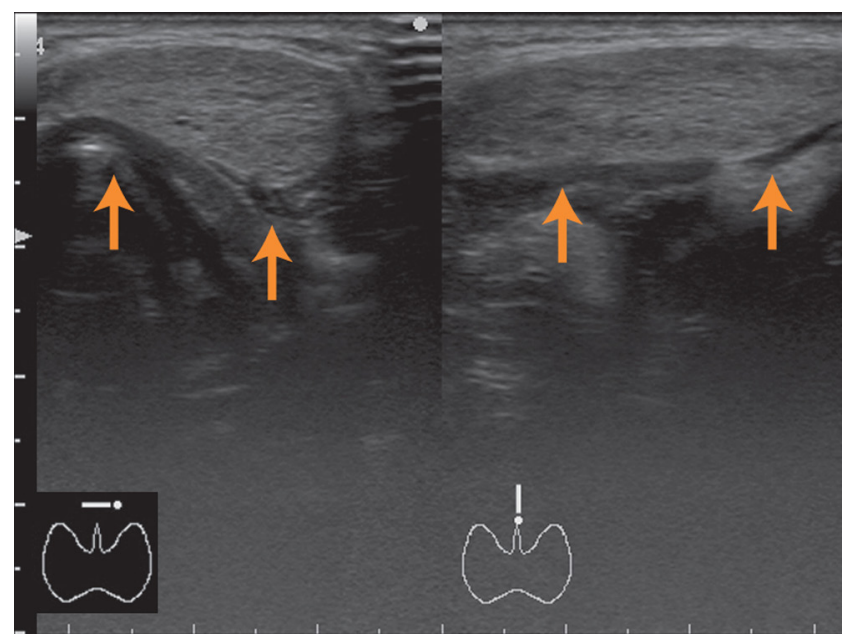

Figure 1

Neck ultrasonography shows a heterogeneously isoechoic mass in the upper part of the neck.

\section{Discussion}

Tc-99m pertechnetate thyroid scintigraphy and CT demonstrated dual ectopic thyroid (lingual and infrahyoid regions), but thyroid tissue in its normal position was not detected by these two procedures. In 2014, Meng et al. (2) studied 42 patients with dual ectopic thyroid including their own six patients and reported that one lesion is in the lingual (sublingual) region and the other is in the subhyoid (infrahyoid) region in about half of the patients. In 2015, Gu et al. (3) identified five patients with dual ectopic thyroid among 42 patients with ectopic thyroid. Among these five patients, four had ectopic thyroid tissue in the lingual and anterior neck regions, one in the lingual

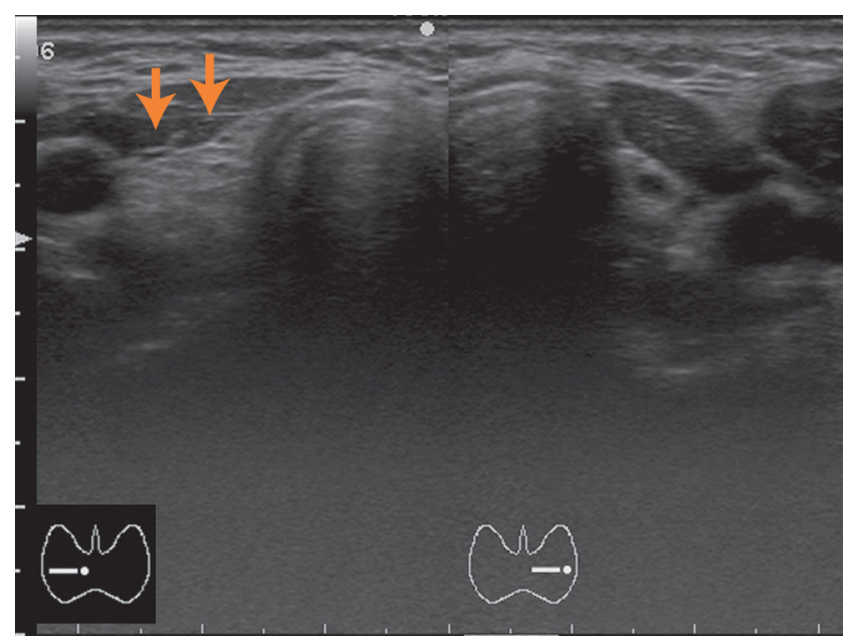

Figure 2

Neck ultrasonography shows an atrophic right thyroid lobe, but no left thyroid lobe is detected. 


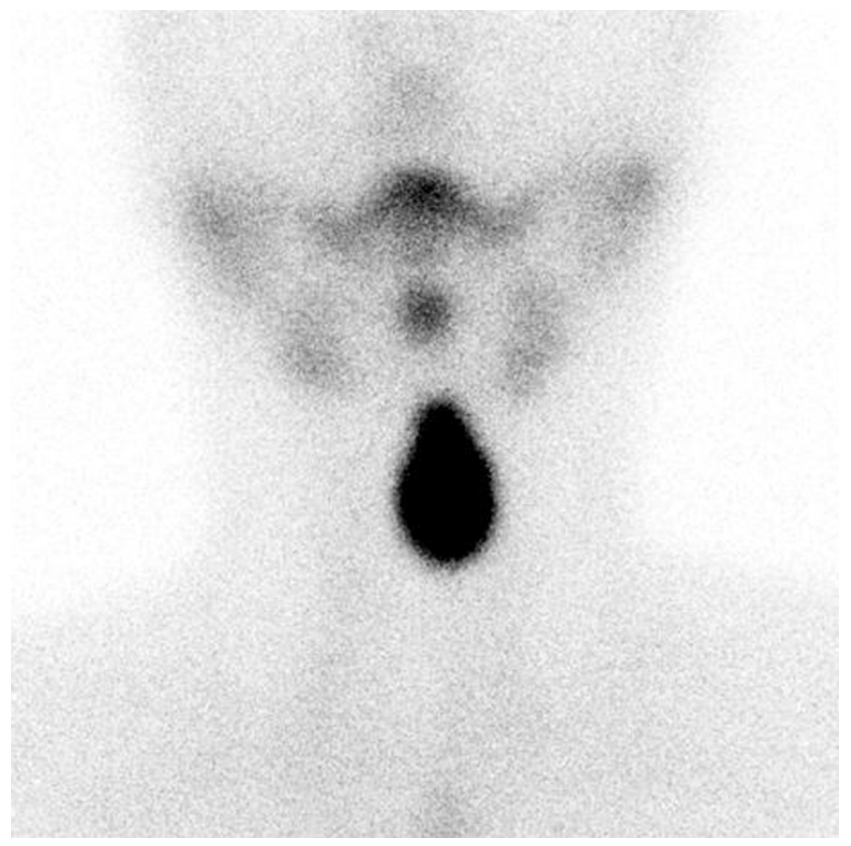

Figure 3

Tc-99m pertechnetate thyroid scintigraphy shows uptake in two regions, the oral cavity and the upper part of the neck, without uptake in the normal position.

region and in the floor of the mouth. Thus, the association of ectopic thyroid tissue with regions above and below the hyoid bone may not be unusual in dual ectopic thyroid. In about $90 \%$ of patients, ectopic thyroid is found at the

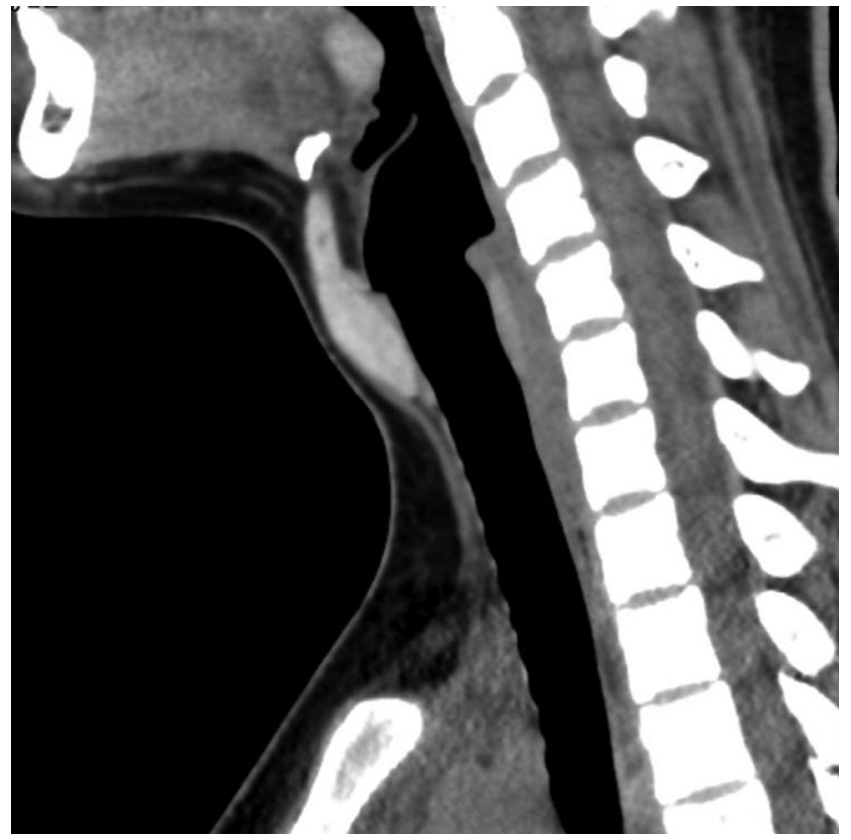

Figure 4

Sagittal CT of the neck shows two masses, one at the base of the tongue and the other in the infrahyoid region. base of the tongue (lingual thyroid) (1). Normal thyroid tissue is absent in $75 \%$ of patients with lingual thyroid (1). In dual ectopic thyroid, a normally located thyroid gland is extremely rare. In 1966, Kuehn et al. (5) reported the first case of dual ectopic thyroid with normal pretracheal thyroid. After this report, orthotopic thyroid glands in dual ectopic thyroid have been demonstrated by scintigraphy or ultrasonography. Karakoc-Aydiner et al. (6) reported that repeated ultrasonography showed the disappearance of previously detected orthotopic atrophic thyroid tissue in six patients with ectopic thyroid. Thus, the atrophic right lobe in our patient may disappear in the future because of the non-functional features.

Ectopic thyroid gland typically becomes evident during adolescence or pregnancy since the requirement for thyroid hormones increases during this period. About $55 \%(23 / 42)$ of the patients with dual ectopic thyroid are also reported to seek medical consultation when they are between 11 and 28 years of age (2). The treatment with L-T4 was stopped in our patient at 11 years of age. This stopping might have increased the size of dual ectopic thyroid mass gradually resulting in the symptoms.

A few reports on patients examined by thyroid scintigraphy demonstrated the association of thyroid hemiagenesis with single $(7,8)$ or dual ectopic thyroid (9). In these reports $(7,8,9)$, orthotopic thyroid is clearly demonstrated, whereas ectopic thyroid is slightly visible by scintigraphy. On the other hand, orthotopic thyroid (hemithyroid) was not demonstrated by scintigraphy or CT in our patient, but was demonstrated by ultrasonography. Silva et al. (10) reported that ultrasonography demonstrated thyroid tissue in 6 out of 18 patients scintigraphically diagnosed as having thyroid agenesis. The right thyroid lobe was atrophic and non-functional and had a low iodine concentration. These features may explain why the right thyroid lobe was not visible on CT. Therefore, not only thyroid scan or CT, but also ultrasonography is required to confirm the presence or absence of orthotopic thyroid tissue in patients with ectopic thyroid. This may be the first reported case of dual ectopic thyroid associated with hemiagenesis detected only by ultrasonography.

\section{Declaration of interest}

The authors declare that there is no conflict of interest that could be perceived as prejudicing the impartiality of the research reported.

\section{Funding}

This research did not receive any specific grant from any funding agency in the public, commercial or not-for-profit sector. 


\section{Patient consent}

Written informed consent for publication of her clinical details and/or clinical images was obtained from the parent of the patient.

\section{Author contribution statement}

S Nakamura wrote the majority of the paper. T Masuda and M Ishimori wrote and contributed as well. Every author played a significant role in drafting this case report.

\section{References}

1 Guerra G, Cinelli M, Mesolella M, Tafuri D, Rocca A, Amato B, Rengo S \& Testa D. Morphological, diagnostic and surgical features of ectopic thyroid gland: a review of literature. International Journal of Surgery 201412 (Supplement 1) S3-S11. (https://doi.org/10.1016/j. ijsu.2014.05.076)

2 Meng Z, Lou S, Tan J, Jia Q, Zheng R, Liu G, Zhu M, He Q \& Li D. Scintigraphic detection of dual ectopic thyroid tissue: experience of a Chinese tertiary hospital. PLOS ONE 20149 e95686. (https://doi. org/10.1371/journal.pone.0095686)

3 Gu T, Jiang B, Wang N, Xia F, Wang L, Gu A, Xu F, Han Y, Li Q \& $\mathrm{Lu}$ Y. New insight into ectopic thyroid glands between the neck and maxillofacial region from a 42-case study. BMC Endocrine Disorders 201515 70. (https://doi.org/10.1186/s12902-015-0066-6)
4 Korpal-Szczyrska M, Kosiak W \& Swieton D. Prevalence of thyroid hemiagenesis in an asymptomatic schoolchildren population. Thyroid 200818 637-639. (https://doi.org/10.1089/thy.2007.0408)

5 Kuehn PG, Newell RC \& Reed JF. Exophthalmos in a women with lingual, subhyoid and lateral-lobe thyroid glands. New England Journal of Medicine 1966274 652-654. (https://doi.org/10.1056/ NEJM196603242741204)

6 Karakoc-Aydiner E, Turan S, Akpinar I, Dede F, Isguven P, Adal E, Guran T, Akcay T \& Bereket A. Pitfalls in the diagnosis of thyroid dysgenesis by thyroid ultrasonography and scintigraphy. European Journal of Endocrinology 2012166 43-48. (https://doi.org/10.1530/ EJE-11-0140)

7 Hsu CY \& Wang SJ. Thyroid hemiageneis accompanying an ectopic sublingual thyroid. Clinical Nuclear Medicine 199419 546. (https:// doi.org/10.1097/00003072-199406000-00019)

8 Aydogan F, Aydogan A, Akkucuk S, Ustun I \& Gokce C. Thyroid hemiagenesis, ectopic submandibular thyroid tissue, and apparent persistent subclinical thyrotoxicosis. Thyroid 201323 633-635. (https://doi.org/10.1089/thy.2012.0079)

9 Velayutham K, Mahadevan S, Velayutham L, Jayapaul M, Appakalai B $\&$ Kannan A. A case of hemiagenesis of thyroid with double ectopic thyroid tissue. Indian Journal of Endocrinology and Metabolism $2013 \mathbf{1 7}$ 756-758. (https://doi.org/10.4103/2230-8210. 113717)

10 De Silva A, Jong I, McLean G, Bergman P, Rodda C, Brown J \& Nandurkar D. The role of scintigraphy and ultrasound in the imaging of neonatal hypothyroidism: 5-year retrospective review of single-centre experience. Journal of Medical Imaging and Radiation Oncology 201458 422-430. (https://doi.org/10.1111/17549485.12166)

Received in final form 1 April 2018

Accepted 12 April 2018 